\title{
Spontaneous and Traumatic Splenic Rupture: Retrospective Clinical, B-Mode and CEUS Analysis in 62 Patients
}

\section{Spontane und traumatische Milzruptur: Retrospektive Analyse klinischer, B-Bild und CEUS-Daten bei 62 Patienten}

\section{(다 (1) $(8) \ominus$}

Authors

M. Rosling ${ }^{3}$, C. Trenker ${ }^{1}$, A. Neesse ${ }^{2}$, C. Görg ${ }^{3}$

\section{Affiliations}

1 Klinik für Hämatologie, Onkologie, Immunologie, Universitätsklinikum Gießen und Marburg, Philipps Universität Marburg

2 Klinik für Gastroenterologie und gastrointestinale Onkologie, Universitätsklinikum Göttingen

3 Interdisziplinäre Ultraschallzentrum, Universitätsklinikum Gießen und Marburg, Philipps Universität Marburg

Key words

CEUS, splenic rupture, spleen, rupture

$\begin{array}{ll}\text { received } & 08.09 .2017 \\ \text { revised } & 11.11 .2017 \\ \text { accepted } & 06.12 .2017\end{array}$

Bibliography

DOI https://doi.org/10.1055/s-0043-125311

Ultrasound Int Open 2018; 4: E30-E34

(c) Georg Thieme Verlag KG Stuttgart · New York

ISSN 2199-7152

Correspondence

Prof. Dr. Christian Görg

Interdisziplinäres Ultraschallzentrum Marburg

Universitätsklinikum Marburg

Baldingerstr.

37043 Marburg

Tel.: +49/6421/586 1538, Fax: + 49/6421/586 2825

Christian.goerg@med.uni-marburg.de

\section{ABSTRACT}

Introduction Both B-mode ultrasound and contrast-enhanced ultrasound (CEUS) are well established procedures when diagnosing traumatic splenic ruptures (TSR). To date, there are no data about CEUS patterns in spontaneous splenic ruptures (SSR). It remains unknown whether TSR and SSR differ with respect to clinical characteristics, B-mode and CEUS characteristics.

Patients and Methods Between 12/2003 and 2/2010, $n=33$ SSRs and $n=29$ TSRs were diagnosed in a tertiary referral center. All patients were examined with B-mode and CEUS, and clinical data and the outcome were retrospectively analyzed.

Results Patients with SSR were significantly older than patients with TSR ( 62 years vs. 44 years; $p=0.01$ ). The 4 -week mortality was significantly higher in SSR than in TSR (36\% vs. $0 \% ; p=0.001)$. No differences between the grading of TSR and SSR could be shown in B-mode or in CEUS. Notably, CEUS was significantly superior to $B$-mode with respect to the grading of splenic ruptures $(p=0.01)$. Therefore, therapeutic management was influenced by CEUS.

Conclusion There are differences between SSR and TSR, especially concerning clinical data (age, course of disease and mortality). Regarding the sonographic pattern, SSR and TSR show identical grading. When splenic rupture is suspected, CEUS should always be performed to identify patients at risk who require interventional procedures.

\section{Introduction}

The clinical picture of traumatic splenic rupture (TSR) on computed tomography, B-mode ultrasound and contrast-enhanced ultrasound (CEUS) has already been investigated and well described in several studies [1]. Spontaneous splenic rupture (SSR) occurs much less frequently. SSR is defined as a spontaneous rupture of a dis- eased spleen, mostly due to splenomegaly. Therefore, we hypothesized that SSR may present with a different clinical and sonographic pattern and may have a different prognosis compared to TSR. The etiology, symptoms, diagnosis, B-mode appearance, treatment and clinical course have only been sporadically described for SSR [2-4]. Furthermore, to the best of our knowledge, there is no de- 


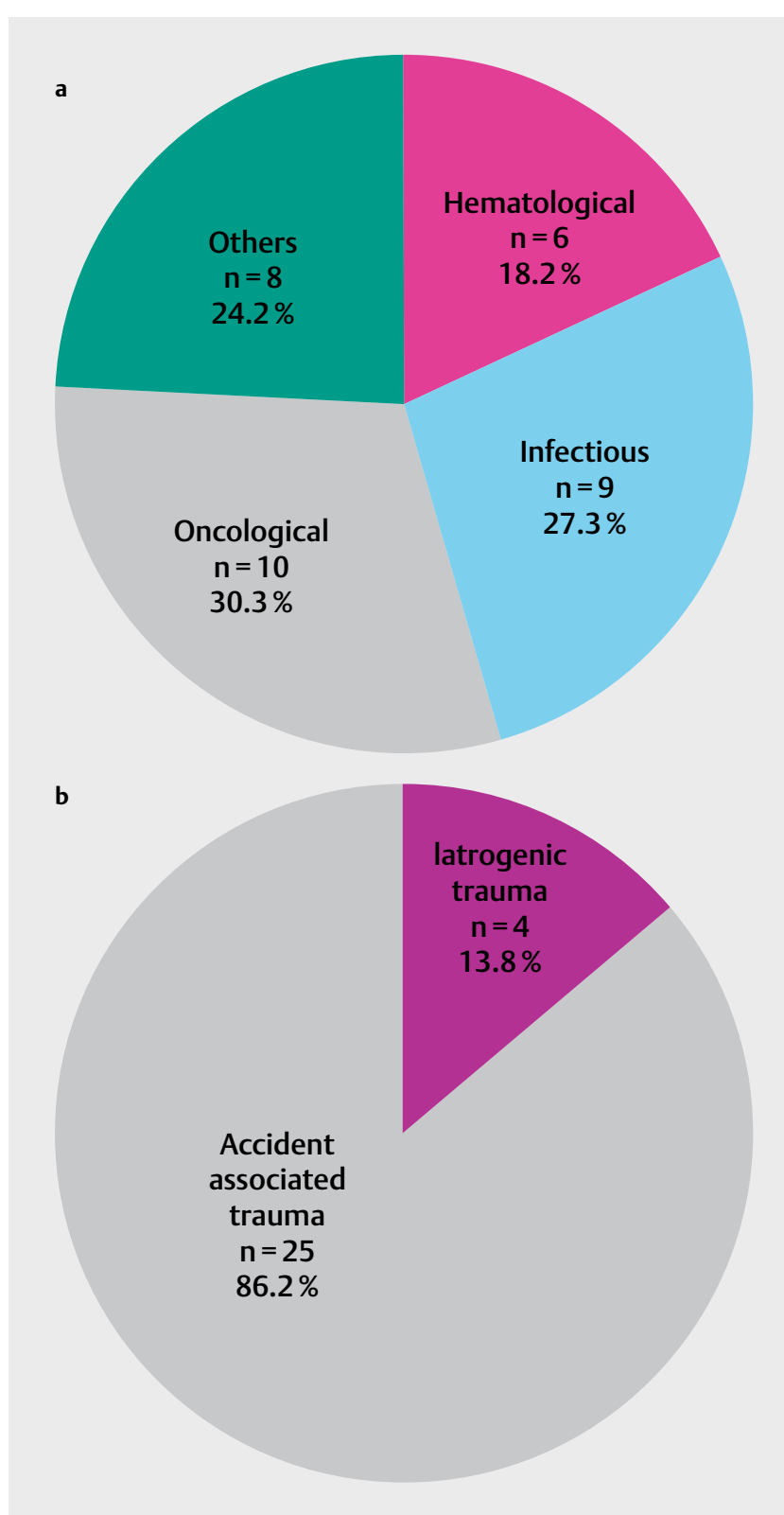

- Fig. 1 Underlying diseases in $\mathrm{n}=33$ patients with spontaneous splenic rupture a; cause of trauma in. $n=29$ patients with traumatic splenic rupture $\mathbf{b}$.

scription of CEUS patterns of SSR in the literature. In this 7-year retrospective study from a university ultrasound center, TSR and SSR were analyzed and compared regarding the clinical picture, sonographic appearance and grading, both in B-mode and CEUS. Moreover, the clinical course and potential therapeutic implications were investigated for both conditions.

\section{Patients and methods}

Between $12 / 2003$ and $2 / 2010, n=62$ consecutive patients with sonographic diagnosis of splenic rupture by B- mode and CEUS in an interdisciplinary ultrasound center were included in this retrospective study. CEUS investigations were performed according EFSUMB guidelines [5]. CEUS was performed with an ACUSON SEQUOIA 512 (Siemens) ultrasound machine which uses contrast-spe-
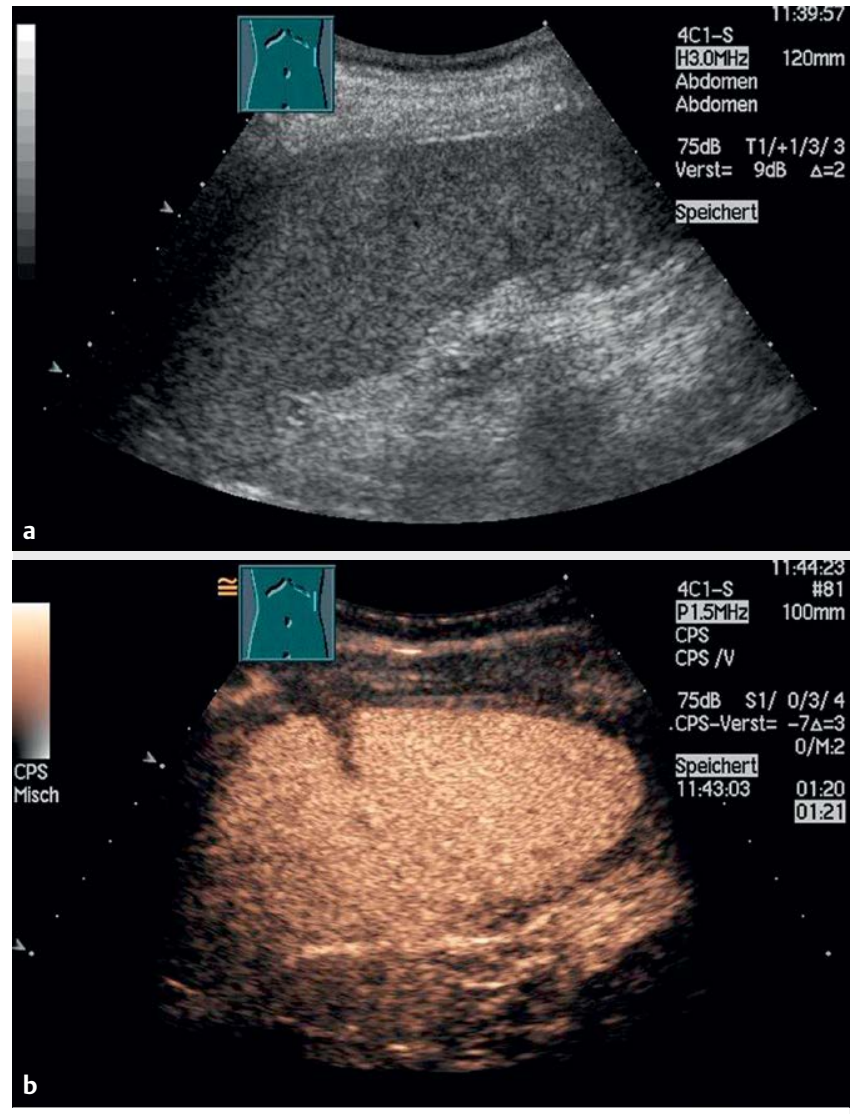

- Fig. 2 a,b: 18-year-old patient in car accident. Diagnosis: traumatic splenic rupture (TSR) B-mode: no grading a CEUS: parenchymal hematoma, grade 2 b Value of CEUS: higher grading Value of CEUS for diagnosis: setting of diagnosis Value of CEUS for therapy: no value Therapy: conservative treatment.

cific software with a low mechanical index. $2.4 \mathrm{ml}$ of second-generation contrast media (SonoVue, Bracco) was administered, followed by $5-10 \mathrm{ml}$ of saline. The splenic parenchymal lesions detected in grayscale imaging were continuously observed over a period of 1-5 min during CEUS. Video clips of CEUS were recorded. CEUS images of the clips were then analyzed.

The following grading system was used $[2,6,7]$ :

Grade 1: perisplenic blood ("sentinel clot") without subcapsular splenic hematoma and without intraparenchymal bleeding;

Grade 2: subcapsular hematoma: diameter $<3 \mathrm{~cm}$, or intraparenchymal bleeding/laceration: diameter $<3 \mathrm{~cm}$ with sonomorphologically intact splenic capsule, or;

Grade 3: subcapsular hematoma: diameter $>3 \mathrm{~cm}$, intraparenchymal bleeding/laceration: diameter $>3 \mathrm{~cm}$ with sonomorphologically intact splenic capsule, or moderate free intra-abdominal pool of blood;

Grade 4: fragmentation of the spleen with the capsule torn apart, or lack of evidence of intraparenchymal blood flow in most parts of the spleen, or detection of arterial flow signal in liquid areas within the splenic parenchyma by CEUS (intraparenchymal pseudoaneurysm), or a high amount of free intra-abdominal pool of blood. 

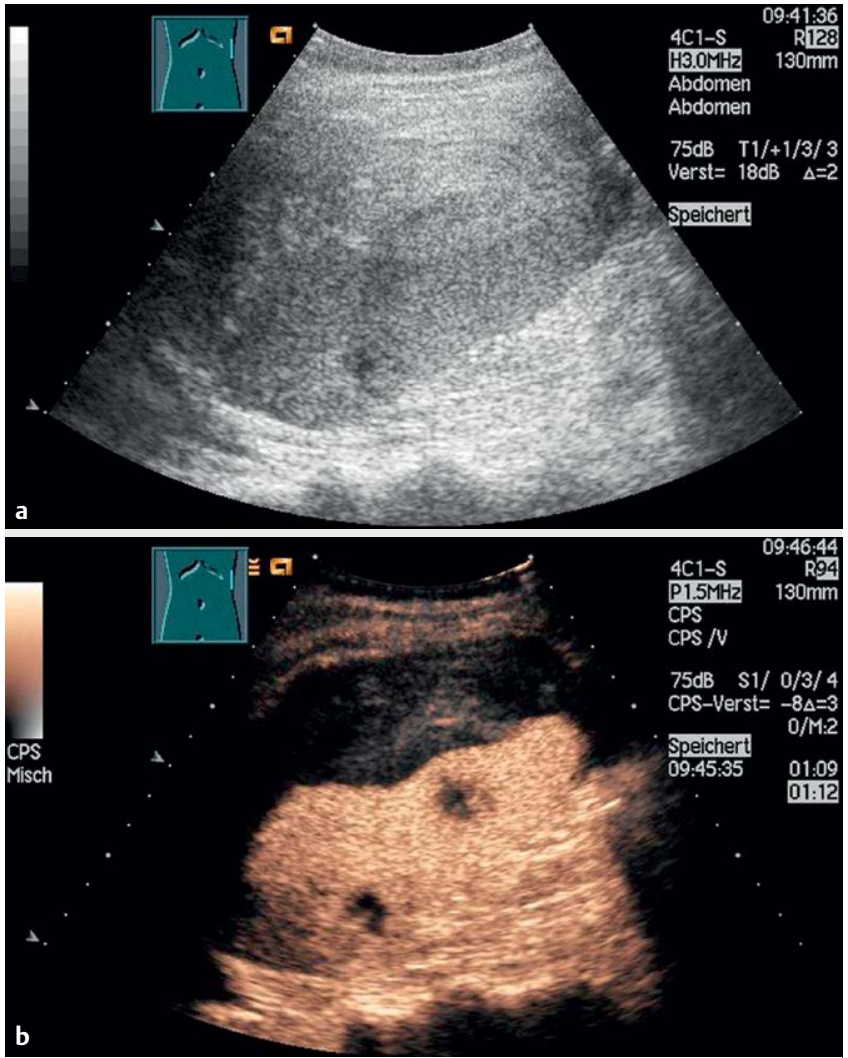

Fig. 3 a,b: 24-year-old patient with angiosarcoma. Diagnosis: spontaneous splenic rupture (SSR) B-mode: subcapsular hematoma, grade 3 a CEUS: parenchymal hematoma, splenic metastasis, active bleeding, grade $\mathbf{4} \mathbf{b}$ Value of CEUS: higher grading Value of CEUS for diagnosis: advanced information regarding diagnosis Value of CEUS for therapy: yes Therapy: urgent splenectomy.

The following data were collected: 1. type of splenic rupture (SSR, TSR), 2. demographic data (age, sex), 3. clinical data (underlying diseases, indication for US investigation (US as primary diagnostic procedure, follow-up investigation after primary CT diagnosis), therapy (conservative follow-up, interventional radiology, surgery), mortality after 4 weeks of diagnosis of splenic laceration), 4. B-mode US data (splenic size, grading of splenic rupture), 5. value of CEUS data regarding grading, diagnosis and therapy in comparison to B-mode US.

The Fisher's exact test and Mann-Whitney U-test were used for statistical analysis. For all tests, a significance level of $p \leq 0.05$ was chosen.

\section{Results}

Ruptures were spontaneous in $\mathrm{n}=33$ patients $(53.2 \%)$ and traumatic in $n=29$ patients (46.8\%). Underlying diseases and causes are shown in $>$ Fig. 1.

$\mathrm{N}=21$ patients $(33.9 \%)$ were female and $\mathrm{n}=41$ patients $(66.1 \%)$ were male. Patients ranged in age between 12 and 89 years (median: 53.5 years). Patients with SSR were older than patients with $\operatorname{TSR}(\mathrm{p}=0.01)$.

Mortality was significantly higher in patients with SSR than in patients with TSR $(p<0.001)$.
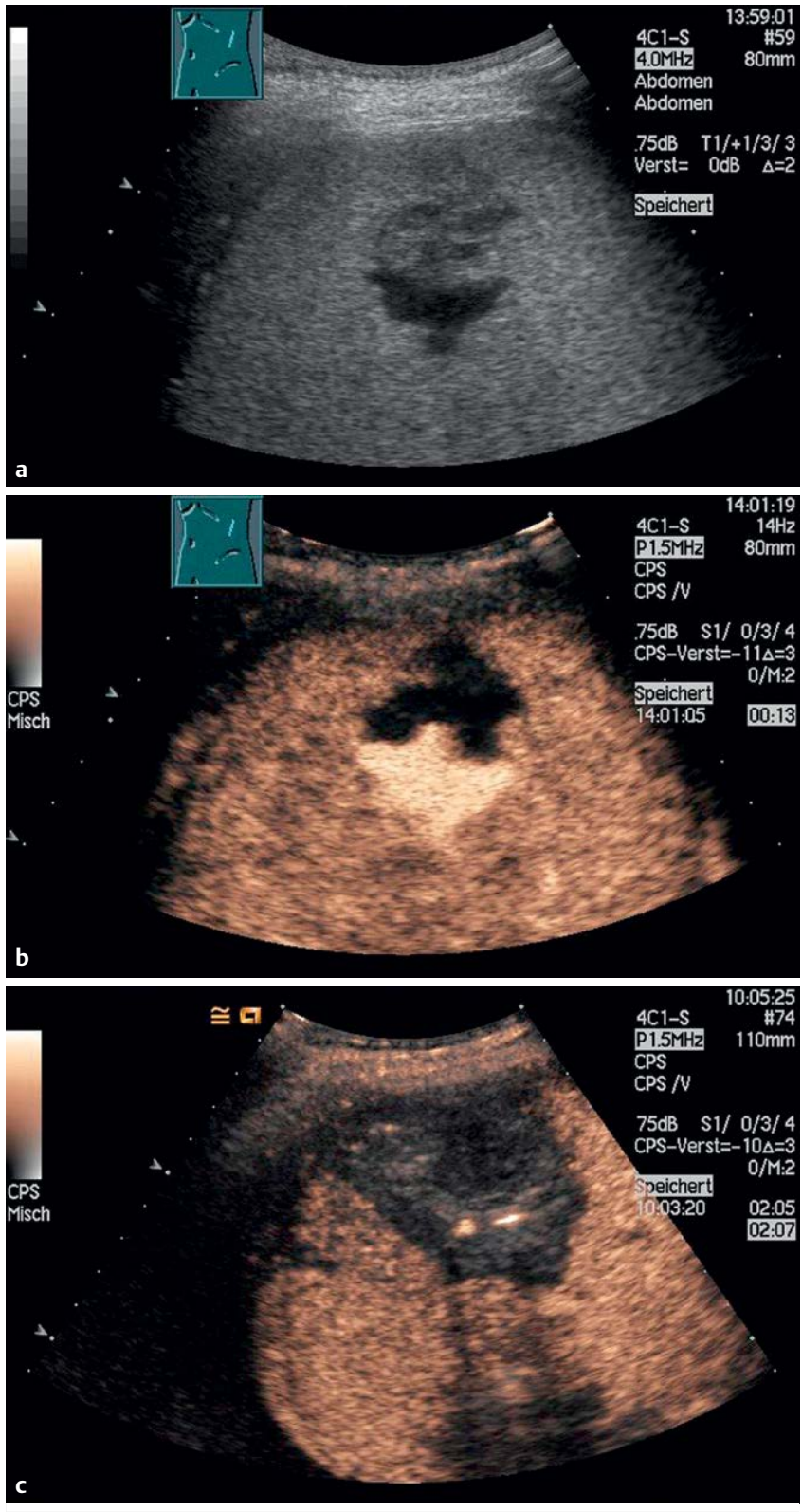

- Fig. 4 a-c: 40-year-old patient with acute leukemia Diagnosis: spontaneous splenic rupture (SSR) B-mode: nonspecific findings, grade 2 a CEUS: infarction, NTISP, grade $4 \mathbf{b}$ Value of CEUS: higher grading Value of CEUS for diagnosis: setting of diagnosis Value of CEUS for therapy: yes Therapy: interventional radiologic embolization c.

Further results were compared between both subgroups and are shown in $>$ Table 1.

Comparison of B-mode and CEUS grading in all patients $(n=62)$ with splenic rupture showed no differences between both subgroups regarding variable grade 4 rupture $(p=0.576)$.

The result of $B$-mode and CEUS grading of all $n=62$ patients with SR showed higher grading for grade 4 laceration in CEUS ( $p=0.005)$ than in B-mode US. Nonspecific findings or impossible grading was seen more often in B-mode US than in CEUS $(p<0.001)$ (Fig. 2-4).

Causes of high-grade SR (grade 4) detected by B-mode were nonspecific findings with high amounts of free intraabdominal 
- Table 1 Summary of clinical and sonographic results of $n=62$ patients with splenic rupture compared between subgroups of spontaneous and traumatic splenic rupture (SR) and with p-values.

\begin{tabular}{|c|c|c|c|c|}
\hline & All patients & Spontaneous SR & Traumatic SR & p-value \\
\hline Demographic and clinical data & $n=62(100 \%)$ & $n=33$ & $n=29$ & \\
\hline Age (average) & 53.5 years & 61.8 years & 44 years & 0.01 \\
\hline $\begin{array}{l}\text { Indication for US investigation: Follow-up after primary } \\
\text { CT diagnosis }\end{array}$ & $43.5 \%$ & $30.3 \%$ & $58,6 \%$ & n.s. \\
\hline Indication for US investigation: incidental & $24.2 \%$ & $36.4 \%$ & $10,3 \%$ & 0,02 \\
\hline $\begin{array}{l}\text { Interventional therapy (surgery or interventional } \\
\text { radiology) }\end{array}$ & $41.3 \%$ & $45.5 \%$ & $34,4 \%$ & n.s. \\
\hline $\begin{array}{l}\text { Follow-up } \\
\text { (alive } 4 \text { weeks after diagnosis) }\end{array}$ & $80.6 \%$ & $63 . .6 \%$ & $100 \%$ & $<0.001$ \\
\hline \multicolumn{5}{|l|}{ Imaging data } \\
\hline Splenomegaly & $71 \%$ & $78.7 \%$ & $62 \%$ & 0.17 \\
\hline \multicolumn{5}{|l|}{ Value of CEUS data } \\
\hline Grade 4 (high-grade rupture) in B-mode US & $6.5 \%$ & $6.1 \%$ & $6.9 \%$ & n.s. \\
\hline Grade 4 (high-grade rupture) in CEUS & $29 \%$ & $33.3 \%$ & $24.1 \%$ & n.s. \\
\hline Value of CEUS for higher grading & $69.4 \%$ & $66.7 \%$ & $72.4 \%$ & n.s \\
\hline Value of CEUS for diagnosis & $58.1 \%$ & $51.5 \%$ & $65.5 \%$ & n.s. \\
\hline Value of CEUS for therapy & $14.5 \%$ & $15.2 \%$ & $13.8 \%$ & n.s. \\
\hline
\end{tabular}

- Table 2 Diagnosis, grading, and therapy of $\mathrm{n}=9$ splenic ruptures with value of CEUS regarding therapy.

\begin{tabular}{|c|c|c|c|c|c|c|}
\hline No. & Clinical diagnosis & B-mode US diagnosis & Grade B-mode & CEUS diagnosis & Grade CEUS & Therapy \\
\hline 1 & $\begin{array}{l}\text { SSR, acute } \\
\text { pancreatitis }\end{array}$ & $\begin{array}{l}\text { Nonspecific findings, } \mathrm{SH} \text {, } \\
\text { FF }\end{array}$ & 4 & $\begin{array}{l}\mathrm{SH}, \mathrm{PH}, \mathrm{FF} \text {, active } \\
\text { bleeding }\end{array}$ & 4 & Splenectomy \\
\hline 2 & SSR, acute leukemia & Nonspecific findings & 2 & $\begin{array}{l}\text { NTISP within } \\
\text { infarction }\end{array}$ & 4 & $\begin{array}{l}\text { Interventional } \\
\text { radiology }\end{array}$ \\
\hline 3 & TSR, trauma & Nonspecific findings & 2 & TISP & 4 & Splenectomy \\
\hline 4 & SSR, acute leukemia & Nonspecific findings & 2 & $\begin{array}{l}\text { NTISP within } \\
\text { infarction }\end{array}$ & 4 & urgent splenectomy \\
\hline 5 & $\begin{array}{l}\text { SSR, malignant } \\
\text { lymphoma }\end{array}$ & Nonspecific findings, FF & 4 & $\begin{array}{l}\text { NTISP within } \\
\text { infarction, FF, active } \\
\text { bleeding }\end{array}$ & 4 & Urgent splenectomy \\
\hline 6 & $\begin{array}{l}\text { TSR, motor bike } \\
\text { accident }\end{array}$ & Nonspecific findings & 2 & TISP & 4 & Conservative treatment \\
\hline 7 & SSR, angiosarcoma & $\mathrm{SH}, \mathrm{FF}$ & 3 & $\begin{array}{l}\text { SH, FF, metastases } \\
\text { active bleeding }\end{array}$ & 4 & Splenectomy \\
\hline 8 & $\begin{array}{l}\text { TSR, motor bike } \\
\text { accident }\end{array}$ & Nonspecific findings & 3 & $\begin{array}{l}\text { TISP within } \\
\text { infarction }\end{array}$ & 4 & Delayed splenectomy \\
\hline 9 & SSR, endocarditis & Infarction & 2 & $\begin{array}{l}\text { NTISP within } \\
\text { infarction }\end{array}$ & 4 & $\begin{array}{l}\text { Interventional } \\
\text { radiology }\end{array}$ \\
\hline
\end{tabular}

(SSR = spontaneous splenic rupture, $\mathrm{TRS}=$ traumatic splenic rupture, subcapsular hematoma (SH), parenchymal hematoma (PH), free abdominal fluid (FF), non-traumatic intrasplenic pseudoaneurysm (NTISP), traumatic intrasplenic pseudoaneurysm (TISP))

blood $(n=2)$, subcapsular hematoma with high amounts of free intraabdominal blood $(n=1)$, and large intraparenchymal hematoma $(n=1)$. Causes of high-grade SR (grade 4$)$ detected by CEUS were intrasplenic pseudoaneurysm (ISP) ( $n=9 ; 14.5 \%$ ) with spontaneous ISP in $n=5$ and traumatic ISP in $n=4$ patients, active bleed- ing $(n=3 ; 4.8 \%)$, one patient with simultaneous traumatic ISP, lack of evidence of intraparenchymal blood flow in most parts of the spleen ( $n=7$, two patients with large amount of free fluid).

In $n=9$ patients ( $14.5 \%$ ) CEUS had an impact on therapy. Additional data are shown in $>$ Table 2. 


\section{Discussion}

TSR occurs in 40-50\% of all patients with blunt abdominal trauma [8]. The clinical picture as well as the value of diagnostic imaging techniques, such as CT, B-mode US and CEUS, have been extensively described in large series [9-13]. In contrast to TSR, spontaneous splenic rupture (SSR) is a rare disease and is usually diagnosed in non-surgical departments mostly by ultrasound. Only a few series of the ultrasound patterns of SSR have been reported $[6,14]$. In contrast to TSR, patients with SSR always show an underlying, mostly malignant disease with pathological infiltration or vascularization of an enlarged spleen. The aim of our study was to analyze whether SSR and TSR differ regarding patterns of laceration, grading of rupture, therapeutic management and prognosis.

Significant differences could be found in age, underlying diseases, and most importantly survival. Accordingly, patients with TSR were younger, had fewer occurrences of splenomegaly or a malignant underlying disease, and had no mortality during the first four weeks. In patients with SSR, the increased mortality within the first 4 weeks after diagnosis of the splenic injury is certainly determined by the underlying diseases. This is supported by the fact that no significant differences between traumatic and spontaneous splenic ruptures could be determined regarding the sonographic grading in B-mode US as well as CEUS. Thus, spontaneous splenic rupture caused by a malignant disease may indicate a poor prognosis for these patients. In addition, no differences could be found between SSR and TSR regarding the frequency of various therapeutic procedures such as splenectomy, interventional radiology and conservative management.

As expected, it could be confirmed that CEUS is highly superior to conventional sonography in terms of diagnostic accuracy and the grading of splenic injuries in both subgroups. The frequent occurrence of intrasplenic pseudoaneurysm is worth mentioning and confirmed previous results in the literature [14]. Additionally, CEUS findings had an influence on therapeutic management.

Summary: Patients with spontaneous splenic rupture were older, had more occurrences of splenomegaly, and had a significantly higher mortality within 4 weeks compared to patients with spontaneous splenic rupture. Both subgroups of splenic rupture presented a similar B-mode, CEUS and grading pattern and needed similar therapeutic procedures. As expected, CEUS is generally superior to B-mode US in terms of diagnostic accuracy and correct grading of splenic ruptures. In both subgroups CEUS had an influence on therapeutic management mainly due to the diagnosis of intrasplenic pseudoaneurysm, and in rare cases due to the detection of active bleeding. Based on our findings, we strongly recommend CEUS in all patients with suspected splenic rupture independent of the underlying cause.

This study has several limitations:

1. This monocentric study was performed in a university hospital with a high number of hematological and oncological patients. Thus, the examined group of patients represents a selection.

2. Patients with multiple traumas are commonly not examined by ultrasound. Therefore, the examined group of patients represents a selection.
3. Ultrasound is known to be associated with high interobserver variability. In this study the findings were obtained by only one examiner with DEGUM degree III.

\section{Conflict of Interest}

C. Görg received funding from Bracco Imaging. Bracco Imaging supported CEUS workshops at the University Hospital Marburg and Göttingen. The abstract of the study was presented as a poster to the “Ultraschall 3-Ländertreffen”, Leipzig 2017.

References

[1] Tinkoff G, Esposito T], Reed J et al. American association for the surgery of trauma organ injury scale I: Spleen, liver, and kidney, validation based on the National Trauma Data Bank. J Am Coll Surg 2008; 207: 646-655

[2] Cölle J. Die spontane, nicht traumatische Milzruptur: Klinik, sonographisches Befallsmuster und Verlauf. Dissertation, Phillips-Universität Marburg 2003;

[3] Weaver H, Kumar V, Spencer K et al. Spontaneous splenic rupture: A rare life-threatening condition; Diagnosed early and managed successfully. Am J Case Rep 2013; 14: 13-15

[4] Wehbe R, Raffi S, Osborne D. Spontaneous splenic rupture precipitated by cough: a case report and a review of the literature. Scand J Gastroenterol 2008; 43: 634-637

[5] Piscaglia F, Nolsoe C, Dietrich CF et al. The EFSUMB Guidelines and Recommendations on the Clinical Practice of Contrast Enhanced Ultrasound (CEUS): Update 2011 on non-hepatic applications. Ultraschall Med 2012; 33: 33-59

[6] Görg C, Cölle J, Görg K et al. Spontaneous rupture oft the spleen: ultrasound patterns, diagnosis and follow-up. Br J Radiol. 2003; 76 : 704-711

[7] Schwerk WB, Görg C. Splenic injury: Sonographic investigation. Bildgebung 1991; 58: 199-204

[8] American College of Surgeons Committee on Trauma. Advanced Trauma Life Support for Doctors, Student Course Manual (ATLS). $8^{\text {th }}$ Edition 2008 Chicago: American College of Surgeons; John Fildes: chapter 5: Splenic trauma: 111-126

[9] Smith ], Caldwell E, D'Amours $S$ et al. Abdominal trauma: a disease in evolution. ANZ J Surg 2005; 75: 790-794

[10] Sterlacci W, Heiss S, Augustin F et al. Splenic rupture, beyond and behind: A histological, morphometric and follow-up study of 254 cases. Pathobiology 2006; 73: 280-287

[11] Cokkinos D, Antypa E, Stefanidis K et al. Contrast-enhanced ultrasound for imaging blunt abdominal trauma - indications, description of the technique and imaging review. Ultraschall Med. 2012; 33: 60-67

[12] Catalano O, Lobianco R, Sandomenico F et al. Splenic trauma: evaluation with contrast-specific sonography and a second-generation contrast medium: Preliminary experience. J Ultrasound Med. 2003; 22: 467-477

[13] Gheju I, Venter MD, Beuran M et al. Grade IV blunt splenic injury-the role of proximal angioembolization. A case report and review of literature. J Med Life 2013; 6: 369-375

[14] Görg C, Cölle J, Wied M, Schwerk WB, Zugmaier G. Spontaneous nontraumatic intrasplenic Pseudoaneurysma: Causes, sonographic diagnosis, and prognosis. JCU 2003; 31: 129-134 